\title{
Gender bender agenda: Dame Edna, k. d. lang and Ivana Trump
}

\author{
Adrian Hale \\ Western Sydney University \\ a.hale@uws.edu.au
}

\begin{abstract}
This paper asserts that we accept or reject humorous texts discursively on the basis of what we perceive as authorial agendas. This "authorial agenda spotting" is activated by discursive "triggers", which identify, filter, reject, endorse, or otherwise subjectively interpret the discourse of a textual author. This study was prompted by observing the negative reception of a humorous text by a predominantly Muslim postgraduate student cohort who signalled cultural identity and social cohesion by rejecting a text which subverted gender performance according to their discursive expectations. The study sought to compare this triggered effect with the reception of the same text by a distinctly pre-disposed audience comprised of samesex-attracted bloggers. This reception in turn was contrasted with the reception of the text by mainstream media reviewers. The text itself seems to spark these discursive triggers in all three audiences. It is taken from "The Dame Edna Treatment" (2007), a TV-media entertainment programme, which features the celebrity guests $k . d$. lang and Ivana Trump being "interviewed" by the Australian comedian Barry Humphries in character as "Dame Edna".
\end{abstract}

Keywords: humour, literacy, discourse, triggers, social identity, authorial agenda.

\section{Introduction and background to the study}

This study was prompted by the negative reception of a humorous text by twenty postgraduate students undertaking a subject which deals primarily with Discourse Analysis. The students were enrolled in 2015 at the University of Western Sydney (WSU), a university that has a highly diverse student body: culturally, linguistically, ethnically, and economically. They are representative of the diversity found in the western suburbs of Australia's largest city, where around half of all the nation's immigrants, and the vast majority of its resettled refugees, are located (UWS 2013; UWS 2015; WSROC 2013). Of the cohort of 20 students, only 20\% were born in Australia, with the rest being born in Afghanistan, Iraq, Iran, Saudi Arabia, Palestine, China and Vietnam. Of the $20 \%$ born in Australia, all claimed ancestry from Lebanon, Iran, Turkey or Serbia; none declared 'Anglo' ancestry (UWS 2015). Consistent with general university statistics, where self-identified Muslims constitute "the largest single identifiable group" of students, the majority of the students in the subject identified as Muslim (White 2007; 
UWS 2015). The Muslim population of Australia is, by contrast, assessed at a tiny minority of the general population, or around 2\% (ABS 2013a). Cultural variation in the subject was also indicated by the fact that $80 \%$ of all students used predominantly a language other than English at home, with Arabic being most popular (UWS 2015).

This diversity contrasts strongly with Australia's general population, where most people are born in Australia (69.8\%), most claim ancestral links to the UK (around 65\%), most (76.8\%) speak English as their first language at home (ABS 2013a), and one in every five Australians (22\%) identifies as having no religion (ABS 2013b). Overall, therefore, it would not be an exaggeration to claim that this cohort of students is discursively representative almost exclusively of what would be the minority elsewhere in the nation. Students of this specific set of backgrounds can be meaningfully described as discursively "conservative", or at least more conservative than most other communities in Australia. These students also have strong links, through immigration and religious affiliation, to societies outside Australia which are described as highly conservative (Hassan 2006; Parashar 2012; UWS 2015).

Such a cohort of students was expected to discursively respond in fairly predictable ways to a text which challenges their conservative backgrounds. Indeed, the Dame Edna text was specifically chosen for these students to see what they would do with it, for the purposes of assessment. The students were required to transcribe and analyse (using mixed-methods Discourse Analysis which students synthesised from including, but not limited to, elements from Critical Discourse Analysis, Conversational Analysis, Face Theory and Politeness Theory) the text for a major assessment task: the report was worth $50 \%$ of their overall grade. As part of their analysis, students were encouraged to offer some subjective responses in their report. All students passed this assessment task, with a mean of $71 \%$ across the cohort. This indicated that students were capable of higher-level discourse analysis (as expected for postgraduates) and that they were able to manage the literacy demands of the task and the subject overall.

The text itself was selected as the basis of an assessment item because of its foregrounding of gender as a referent in various forms, and because most students were not familiar with either Dame Edna, k. d. lang or Ivana Trump. Students were expected to explicitly address gender as a social construction and to reflect on its meaning for the text, the students themselves and the textual "players". The text was offered to students as an instance where "linguistic performance of heterosexuality [is of] fundamental importance for the constitution of gender identities and gendered linguistic styles" (Cameron 2005: 495). Students were also asked to look at generational and cultural nuances for gender, noting that "the understanding of $[\ldots]$ what it means to be a woman [...] changes from one generation to the next and [...] this perception varies between different racialised, ethnic and religious groups, as well as for members of different social classes" (Wodak 1997: 4). More generally, students were asked to reflect on implicit ways in which the medium of a text frames the 'message' of the text, or the ways in which "Learning implies acquiring both knowledge itself and the code of transmission used to convey [it]" (Bourdieu et al. 1965: 5). Gender was posited as a central means of framing the text and students were asked to contrast the codes of its various transmissions.

That is, students were expected to comment on the ways in which the "suite" of femaleness as presented in the text, as an obviously deliberate contrivance, works to undermine social expectations of gender performance. The set of gender contradictions is explicitly used in the text as a frame for the purposes of comedy and it is thus a deliberate, central feature of the text itself. After transcribing the textual excerpt, students analysed and commented on the features that they located.

As expected, this mix of communicative competence and conservative outlook produced a marked negativity on the part of students as indicated in their subjective responses. Overwhelmingly, student comments were informed and analytical, but many were also 
dismissive, or at least critical, of the text's subversion of gender roles. This confirmed the expectation that an audience which can be described as predisposed to be negative for reception of the text was demonstrably non-aligned with the authorial discourse and agenda.

Some comments, taken from student reports, are listed below (paraphrased, anonymised and without any other explicit identifying features, such as gender or religion). They are used here for illustrative purposes only.

"I get it, but I don't think it's very funny."

"In my culture, we don't think it is good to dress as a man."

"Why do we study this text?"

"This is a text about a man dressed as a woman, a butch lesbian and a socialite."

"Ivana is showing too much skin"

"Why does this man act like a woman?"

"Perhaps this is Australian humour."

\section{Significance of this initial textual reception: discourse and literacy}

It is clear from these comments that most students were able to process the information well, but resisted the "point" of the humour. This can be defined as, overall, a struggle with the complexity of contextualised humour; a problem presumably compounded by unfamiliarity with gender subversion norms found in the text and in the genre of humour as articulated by Dame Edna and k. d. lang. Cultural resistance was present across all categories of students, and this is significant. It indicates that there is no deterministic relationship between communicative competence and receptivity for a text which demands higher level literacy, but rather the discourse of a person seems to intervene to "block" a positive reception, where positive denotes that a person not only understood the text, but enjoyed it as being humorous. It would also appear that persons, regardless of literacy, are very sensitive to texts when they discern an authorial agenda which is oppositional to their ideology, discourse, or otherwise entrenched normative values. Indeed, it does not seem to matter whether the students had the "extensive knowledge of (Edna's) world and [...] the characters who inhabit it" (Tolson 1991: 191). Some did have this knowledge, but most did not. Familiarity with comic genre and a background knowledge of subversion techniques do not guarantee a positive reception for a text which is subversive of a person's deeply-held ideology/discourse. Indeed, these students clearly demonstrated a higher-level competence - they were able to engage with a text for the purposes of academic analysis - but they still articulated strident objections to the authorial agenda itself.

\section{Frames of reference: conservative and liberal/progressive}

It is important at this point to define what is meant by the terms "conservative" and "liberal/progressive" in the Australian context. If we define a person (or community) as conservative, it is because they have low "flexibility" for "conformity [...] and moralistic" ideas, and because they "positively [endorse] authoritarian attitudes" (Wink et al. 2007: 327, 331). It thus follows that we can define "liberal/progressive" as a person (or community) with high flexibility for conformity and moralistic ideas, and who is also more likely to endorse the subversion of authoritarian attitudes. Or, to put it another way, a conservative in the Australian context is more likely to accept a greater role for religious and/or traditional authority in not only their own life, but also for the lives of other people.

In the Australian context, there is enormous potential for this simple binary to be quite marked, and to assume that Muslims may be more conservative relative to the wider Australian 
community, which is described, by contrast, as a "secular [...] robust civil society" (Hassan 2006: 130). Australia is also described as a nation which is a "modern, liberal state" (Parashar 2012: 572). For example, even though official figures indicate that Christianity remains the dominant religion in Australia (at around $70 \%$ of the population), the active participation rate, including regular Church attendance, is at no more than 8\% (ABS 2013b; Powell et al. 2016). So, while there is a nominal religiosity amongst Australians, it is more tacit, and not supported by active religious participation. Australians also tend to have more liberal views which do not conform to stated religious affiliations. That is, the general Australian community is neither overtly religious nor attitudinally conservative. Indeed, Australia has been referred to as "the most godless place under heaven" (Breward 1988)-perhaps hyperbolic, but with some justification.

There are several reasons for this. Australia is a nation distinguished by a clear separation of Church and State, not only in politics, but also in many liberal/progressive social attitudes, including ideas relating to gender equality. It is a society which typically prioritises "equal respect for men and women, equality of resources and capabilities [and] parity of participation in socially valued activities" (McDonald 2000: 3). In terms of liberalism towards gender, sexual activity and orientation as specific areas of morality, for instance, Australians "tend to have permissive attitudes" (Kelley 2001: 15). As one marker of liberalism, Australians are predominantly (72\%) in favour of same-sex marriage (Cox 2014). These are clearly secular priorities which can cause conflict with certain religious-cultural norms, since "[r]eligious belief makes a huge [negative] difference to tolerance" (Kelley 2001: 18); Australians, in general, are not religious, and thus tend to be tolerant of liberal/progressive views and practises.

Contextually, then, there is evidence for an Australian Muslim identity which is distinctly at variance for the wider Australian community for certain attitudes. Indeed, this identity is as much a self-generated conceptualisation as an externally imposed label. So, for instance, Muslim persons in Australia are more likely to self-identify as having religious belief (at least $90 \%$ ) and to report actively participating in Muslim worship services (ABS 2012). This is contrasted against a wider Australian community which seems to actively discourage overt religious belief. Further, as a matter of belief which translates into practise, in the Australian social environment, Muslims constantly encounter wider norms and "opinions [which are] at variance with standard Islamic views [and which thus] could easily be looked upon as blasphemous" (Hassan 2006: 122). The significance of blasphemy must be understood in the overall context of a belief system which prioritises obedience to religious law (Sharia), a code of practise believed to be of divine authorship, and which has "immutability and compulsory application" (Parashar 2012: 570). In one particular area of conduct, that of moral behaviour as it relates to gender performance, there is clearly a conflict between conservative (or traditional) Muslim ideology and wider Australian (liberal/progressive) community expectations, as informed by feminism. The wider Australian expectation contrasts with conservative Muslim values, because it asserts that "gender equality requires a broader conceptualisation of gender constituted by an interaction of a number of differences" (Parashar 2012: 571).

Of course, this potential ideological conflict can be qualified as an issue of how, in practise, individual Australian Muslims negotiate an essential contradiction between traditional beliefs and the wider environment of secular liberalism. It is, for instance, asserted that, while Australian Muslims have strong links to overseas communities of Muslims through immigration and schismatic religious allegiances, they, reportedly, express far more "moderate views" than Muslims in these other countries (Hassan 2006: 124-125). Further, Australian Muslims do not typically resolve any ideological conflict through a simple dichotomy, by opting "between 'open' and 'closed' dispositions" (Dryzek \& Kanra 2014: 183). Indeed, it would appear that there is a highly "nuanced" set of views represented in the Australian Muslim 
community, offering what could be termed a continuum, or "the universe of discourses among Australian Muslims [which] seems to correspond roughly to what is [a] set of moderate discourses." (Dryzek \& Kanra 2014: 195). Of course, we can also interpret these "moderate" views as being characteristic of an acculturated minority: a person from a minority group can be ideologically opposed to a cultural practise of the majority, but still be moderate in their response to it because they feel, generally, integrated into the community. That does not mean that a Muslim person is in any way tolerant of, or less hostile to, that cultural practise; they just accept that a moderate response is appropriate. This is consistent with the suggestion made by Dryzek and Kanra (2014: 195), who argue that a combination of Australian conditions has produced "the depoliticisation and privatisation of faith" for Muslims in that nation. Indeed, there is evidence that, in the Australian context, where Muslims feel distanced by secular society, there is actually an increase in "personal religious commitment" even if it is more tactfully expressed (Hassan 2006: 128). This is not to say that the conflict "goes away", or that it is less important as a point of contention; it simply means that Muslims feel comfortable enough in Australia to express their opposition to items of ideological conflict in appropriate ways.

Thus, while it can be safely assumed that Australian Muslims are, typically, moderate in their views, we can also assume that there exists a latent defensiveness, as a conservative minority, to any instance of a challenge to traditional views on ideas such as gender performance. It is predictable, therefore, that Muslim responses to the Dame Edna text (which transgresses these conservative views) would be expressed in a moral frame. We could also predict that the responses would be determined by, and express, at least in part, the degree to which the person feels integrated into the wider community. What would put this integration under stress, of course, would be a text which is polarising for its discursive content; and this is precisely the type of response which the Dame Edna text elicited.

\section{Resistance to humour as a discursive defence}

This feature of resistance to a text on the grounds of ideology/discourse, by a person who has high-level communicative competence, invokes what can only be described as a self-defence mechanism against a text which intrudes into that person's ideology/discourse. Or, to put it another way, a person who is perfectly capable of decoding a joke, does not have to enjoy that joke. The pressure to conform to the normative environment of the university setting can be resisted by personal, agential decisions. Resistance can also be linked to external allegiancesin this case, intra-Australian and overseas communities of practise (which are conservative for performance of gender). The fact that these highly literate students genuinely did not enjoy the humorous text indicates that the "orders of discourse at the level of social practises" (Fairclough 2003: 28) are very powerful motivations.

One other point can be made here, which is that students seem to be voluntarily offering a moral frame informed by their conservative discourse in rejecting the authorial agenda of the text-despite what could be viewed as contextual pressure to be acquiescent. That is, students are not only aware of the wider Australian context of secular liberalism; they are located in an educational setting (the modern Australian university) which can be viewed as even more liberal and secular than the wider community. Indeed, the university setting could be viewed as largely antithetical to conservative values in general (Kelley 2001; Hyers \& Hyers 2008). And yet the students were motivated to openly speak out against the textual agenda. This willingness to challenge the authorial agenda might be seen the sign of a confident, integrated minority, but it should more properly be seen as a motivated response to a text which is read by students as explicitly challenging their deeply-held views. In other words, students, despite 
the normatively anti-conservative environment of the university setting, were so offended by a text, that they openly challenged it for its discursive agenda.

From this preliminary textual reception, it can be postulated that in any group of people who share the same high level of communicative competence, a humorous text will be decoded primarily, not on the basis of its intrinsic complexity, or "funniness", but rather on whether it discursively aligns with the wider group to which each person holds allegiance. In this sense, this paper proposes that we, as individuals, decode and assess any humorous text through a type of discursive filter, which we employ to identify the authorial agenda as either a threat or confirmation of our group identity. In order to evaluate this proposition, this paper will firstly present a discussion of relevant theory, before offering a sample analysis of the text itself. It will then present the study of two, disparate groups (mainstream media reviewers and samesex-attracted bloggers) who responded to the Edna text, before deciding whether the results vindicate this proposition. The two groups were selected for oppositional and control reasons. Same-sex-attracted bloggers, as representative of a group of people presumed to be highly liberal ideologically, were presumed to be discursively in a position opposite to the Muslimconservative students. They also, as a sample of a minority (the lesbian-gay community) which is estimated to comprise around $2 \%$ of the overall population (Kelley 2001: 15), were presumed to be especially pre-disposed towards the Dame Edna text, in the same way that the Muslimconservative students were found to be pre-disposed against the text. The control sample was derived from mainstream media reports on the Dame Edna text, and is used as a type of representation of mainstream Australian community attitudes. It was assumed that the mainstream media would be discursively sympathetic to the text, but not necessarily predisposed towards it: since the media authors were professional critics, it was expected that they would maintain some discursive distance.

\section{Text reception as a signal of group identity and natural defensiveness: positivity, negativity and the inert}

The acceptance or rejection of a text has been theorised as being, primarily, a matter of communicative competence (Canale \& Swain 1980; Canale 1983; Celce-Murcia 2007). This notion of literacy is important, such that textual reception is regarded as being informed by a hierarchy of competencies (Reid 2006; Stevens \& Campbell 2008). Certainly literacy is essential to the process of comprehension, whether it is a matter of semantic competence or higher-level pragmatic or discursive knowledge (Kintsch 1998). Indeed, the complexity of such comprehension is not to be underestimated, since the decoding of a text is a cognitive site where complex "[p]rocesses at many different levels interact [including] reading or listening, syntactic and semantic analyses, knowledge integration, as well as reasoning processes" (Kintsch 2005: 127).

However, a high level of language competency in and of itself does not guarantee a standardised, or predictable, reception of a text. A humorous text, in particular, can be very complex and unpredictable in its reception (Lee \& Gunesekera 2006; Wulff et al. 2009; Nesi 2012). This is because the humorous text makes demands on literacy for the processing of script-schemas which overlap and conflict in ways not required of more streamlined, or directly propositional-content/communications (Raskin 1985; Attardo 1994; Hertzog \& Anderson 2000). The amount of mental processing required for humour is immense, given that its contradictory script-schemas add to the existing and "underlying inferential processes [requiring] a wide range of sources of knowledge (linguistic knowledge, pragmatic knowledge, world knowledge, social knowledge, etc.)" (Mayerhofer et al. 2015: 4). 
Moreover, given that humour is also considered to be, by definition, a social act (Chapman 1983; Ross 1998), it has the potential for much greater affect in the validation or subversion of relationships (Holmes \& Marra 2002). Humour, therefore, is provocative, and frequently, divisive. To see it otherwise is to indulge in a "mirage of innocent humour" (Gruner 2000: 147). Indeed, humour in general is seen as having an embedded "impulse [for] aggression [with its] common ingredient [...] the aggressive-defensive or self-asserting tendency" (Koestler 1964: 52).

It is logical, therefore, to assume that in any setting there might be a latent, pre-existing suspicion on the part of the interlocutor, that the author of a humorous text may have an agenda of aggression. The reception of a humorous text will be filtered by the need to protect oneself against potential aggression, particularly where the text signals some embedded, discursive "comment" on the ideology/discourse of the interlocutor. This is particularly true when the group identity of the interlocutor may be representative of a minority, or otherwise powerless group, in society. The interlocutor who is highly literate and operational at the high end of communicative competency, can readily 'get' the joke, but not enjoy it, because they are sensitive (for any number of reasons or motivations) to their reading of the authorial intention, especially where that text operates as a symbol of mainstream, or institutional, power which they do not feel any allegiance to.

This is not to argue that the interlocutor is resisting the text in some sort of unreflexive, automatic response. Rather, the awareness of conflicting social practises can actually be indicative of greater literacy of the ways in which power and social discourses operate (Fairclough 2003). Indeed, when a gap between variant discursive assumptions is identified, or "triggered" (Levinson 1983), it is evident that the interlocutor is operating from a highly literate position having extensive knowledge of how each operates. That is, the interlocutor is clearly aware of how these "existential and propositional assumptions" (Fairclough 2003: 58) work against each other. Resisting a text in this way points to an informed, agential decision on the part of the interlocutor, and it functions as a type of "pragmatic blocking" (Wilson \& Stapleton 2007: 393). The fact that resisting a joke will rely on, and be motivated by, a person's allegiance to a group which is not aligned with the authorial agenda, offers the individual important validation in this choice to resist the joke and to feel empowered in this choice.

By the same token, it is logical that people who are already aligned discursively with the textual author are more likely to enjoy the joke, and that they will do so in awareness of the authorial agenda. This is because they discursively share the "same code" (Critchley 2002a: 67-68). They are also more likely to be aware that this agenda corresponds to, and validates, their own social group identity and ideology/discourse. Indeed, in doing so, they will be making a conscious decision to reference, and to identify with, the group which the joke aligns with and represents.

Both alignment and non-alignment are predispositions towards the humorous text which can operate in opposite ways. This is especially true for a more polarising text which generates what has been labelled the "inclusion/exclusion binary" (Weaver 2013: 485). The text operates to divide people, not so much according to the text itself, but rather according to the interlocutor's preconceived bias towards what a joke is referencing. In responding to a text according to what an individual is already aligned with discursively, that person is using the text to reinforce their way of seeing the world, and, typically, this also functions to validate a person's membership of a group. Or, as Partington (2006: 116) defines it, there are contextualisation triggers required for a positive reception of the humorous text: "[h]umour reception and evaluation are notoriously dependent on context and whether the audience is primed for laughter". A significant factor in this contextualisation and priming, is most certainly a discursive alignment between textual author and audience. Indeed, it is probable that most people actively seek out, or at least only respond positively to, humour which "simply 
seeks to reinforce consensus and [which] in no way seeks to criticise the established order" (Critchley 2002b: 3).

The reception of humour is therefore strongly correlative as a marker of speech group identity: "People laugh in company [...]. There is a strong social aspect to the way people respond to humour [...]. Like other aspects of language, humour is a way in which people show their allegiance to a group" (Ross 1998: 1). Or, as Berger (1997: 57) refers to humour's role in forming and maintaining group identity: "Those who laugh together, belong together". That is why, as John Carey (2003) comments, active participation in a humorous text is strongly motivated by a need for "belonging":

....an element of our enjoyment of these clever jokes is a self-congratulatory awareness of our own cleverness in enjoying them. We feel ourselves to be [...] in the company of clever people like ourselves, and $[\ldots]$ delight in our membership of the closed circle to which the joke can appeal.

(Carey 2003: xvii)

Similarly, humour can operate as a shibboleth or exclusionary token of group identity (Fine \& de Soucey 2005). Failure to negotiate this type of text implies that a person is unable to "belong". This also explains why persons, who are excluded by non-participation in the text, will more keenly feel the lack of membership in this group of "clever" people - not just from the text itself, but also from the power dynamics of those who conform to the group which the text represents. It is this, sometimes explicit but perhaps more often implicit, group identity required in the operation of a humorous text that Critchley (2002b: 3) refers to as the "tacit social contract $[\ldots]$ namely some agreement about the social world in which we find ourselves as the implicit background to the joke [...] a sort of consensus or implicit shared understanding as to what constitutes joking "for us". Indeed, if a provocative text operates in a social sense, it can also be very socially divisive. When we "get" the joke, the reward is not just the enjoyment of the text, but also the social validation it offers. Similarly, the "estrangement" we feel if we do not align with the text is powerful: textually, personally and socially.

It is possible to streamline this discursive humorous textual receptivity in terms of positivity or negativity. Both require some foundational literacy to function: we can state that when a person is functionally, contextually or communicatively illiterate and thus unable to process a humorous text in any meaningful way, there can be no real discursive engagement with that text anyway. This can be referred to as an inert textual response; particularly so because the default human discursive setting seems to be to resist a humorous text as it constitutes a potential act of aggression.

By contrast, a discursively positive reception of text denotes a favourable reception, not just because the propositional content of the text has been successfully decoded, but because some element of the humorous text has triggered, and taps into, a measure of discursive alignment between textual author and audience. Within any active textual response are discursive triggers. Discursive triggers are the items of a text which reference the discourse of the persons involved. When we are aligned, we resolve our need to be discursively defensive, and we give ourselves permission to laugh. Naturally, and by extension, we can refer to the unfavourable reception of a humorous text as a discursively negative response, since it invokes the opposite mechanism. When we are alerted to discursive triggers in a humorous text which we have successfully processed for propositional content, we filter it according to how it constitutes a threat to our discourse. If we are not aligned with the authorial agenda-discourse, we reject it, and to at least some level, we consciously decide to refrain from laughing.

This offers a mechanism for explaining the negative reception that the text had with a conservative student audience, where the performance of gender in the text presented a very salient discursive trigger. By way of further analysis, we can now move to a closer examination of the text itself, to see where specific triggers operate to polarise audiences. 


\section{The Edna text: performances of gender}

The Edna text is a five minute excerpt from one episode of "The Dame Edna Treatment" (2007), a British-produced TV-media entertainment programme, which features the celebrity guests k. d. lang and Ivana Trump being "interviewed" by the Australian comedian Barry Humphries in character as "Dame Edna Everage". All the "players" in this text, which is described for genre as a "comedy-chat show" (IMDb 2015), present variant expressions of femaleness. It should be noted here, that while Dame Edna is most familiar to Australian audiences, the text has some international currency for recognition; both k. d. lang, who is Canadian, and Ivana Trump, who is a naturalised US citizen, are well-known internationally. Further, Dame Edna has performed for both UK and US audiences for several decades, and it is this international combination of performers which audiences seem quite able to reference. Even though some of the (US-based) same-sex-attracted bloggers were, by their own admission, previously unfamiliar with Dame Edna, they were familiar with $\mathrm{k}$. d. and Ivana. From this background knowledge, most of them were able to discern the parody and referential links being presented by the show's host. Similarly, for the UWS students who were typically unfamiliar with any of the participants (explainable by the fact that several of the students were recent migrants from countries such as Iraq and Afghanistan), there was a gap in background knowledge. However, it is argued that this was not necessarily a disadvantage. On the contrary, an audience which is being forced to generate their own links between performers actually enhanced the data: it means that the audience needed to draw on their own discursive preconceptions of gender performance to make sense of the text.

Of the three participants, Ivana Trump presents as the most heterosexual character. Perhaps this is why, as a guest, and in this excerpt, she is sidelined by the interview between $\mathrm{k}$. d. lang and Dame Edna. She had previously, in the same episode (just prior to this excerpt), been the subject of an interview by Edna, and is now a passive guest as Edna foregrounds k. d. As a career socialite, Ivana presents as a type of "hyper-cis-hetero-female", sexualised character, complete with a bright red, revealing dress and plastic surgery, but without any (apparent) selfawareness of irony as the only heterosexual female present in the interview. Her name is a blend of her Czech birth-name and the patronymic surname adopted upon marriage to Donald Trump: and it is emblematic of her socialite "credentials". It is interesting also that Ivana, who at the time of the text was a 58 year-old woman whose main claim to celebrity is as the ex-wife of a property tycoon, and as a person with weaker English-language skills, seems to be comfortable performing as the passive female in a public forum. The contrast between the "fading" socialite (Ivana) and the suburban housewife turned-Gigastar (Edna) highlights the ways in which Ivana performs gender — as the passive "image of desire" (Doane 2004: 98). It also indicates that if Ivana is relying on her physical capital for meaning as a woman, she is, contextually and inferentially, being set up as a parody of femaleness by being on this show with Edna and k. d.

Barry Humphries, an Australian heterosexual male comedian, has built an internationally successful career spanning decades particularly in the UK and Australia, but also in Canada, the USA and New Zealand (Tolson 1991; Turnbull 2008). In this programme, he presents in "drag" as his most famous character, Dame Edna Everage: the character's name offering a juxtapositional punning of an aristocratic honorific with "average" and a first name (Edna) which is generationally specific for denoting an older woman. Edna's self-characterisations have evolved over time, being referred to originally as a "suburban housewife" and then "Dame" to the later "Megastar" and finally as "Gigastar" (Turnbull 2008). The character is positioned as a naïve suburban woman of somewhat advanced age (Humphries was 73 years old at the time of the textual production), with the sociolect and aspirational discourse ill-suited (deliberately, for comedic purposes) to interviewing celebrities. Edna's lilac-coloured, outsized 
wig, sequinned gown and ostentatious jewellery, including diamante-encrusted eyewear, are semiotic devices deliberately selected to represent both a "drag" version of the "hyper-female", as well as being a caricature of the pretentious suburban female with "petty bourgeois values" (Tolson 1991: 191). Indeed, it is the very aspirational nature of this suburban bourgeois female character to celebrity status which is referenced by the self-applied labels: Dame/Megastar/Gigastar. It is this combination of older female naiveté and pretentiousness which is at the heart of Edna's comic utterances, as the character transgresses social norms of politeness both for the chat show and for broaching "sensitive or taboo issues [and neglecting] rites of deference to guests" (Lockyer \& Pickering 2009: 194).

The Canadian singer, k. d. lang, by contrast, presents as a gender-indeterminate person with male-typical business suit and tie. This is consistent with her overtly stated same-sex orientation, her on-stage persona, her music, and her fan-base. The use of a lower case, nongender specific and initialised stage-name as part of this character adds to her performance of gender as androgynous. k. d.'s performance of gender is quite contrastive, or marked, when contextualised against Edna and Ivana, who perform recognisable, ideologically unmarked 'heterosexual' female roles. Indeed, k. d., aged 46 at the time of the textual production, is the youngest of the participants, but, interestingly, probably the person for whom physical capital (or "looks") are the least important. She is not wearing any make-up (other than the obligatory studio minimum) and seems the least self-conscious about her performance of gender, particularly under the public gaze. Indeed, she seems content to sidestep any obvious display of "femaleness" according to either clothing or age norms. So, for instance, as a middle-aged woman, there is nothing in her dress or manner which defines her as a woman of this agegroup. The obvious contrast is with Ivana, who seems to be asserting heterosexual female youth and attractiveness (with dubious results), while $\mathrm{k}$. d. is performing femaleness without any reference to sexual appeal or age-specificity. Thus, k. d. appears to overturn "negative stereotypes of the aging female" (Vertinsky 2002: 61) by not performing any obvious genderspecific role.

Of course, these performers in the text are not individually the focus of the humorous performance: it is their combination which functions to contextualise the theme of gender performance, and that is where the humour is derived. We must conclude that this paradoxical, or ironic, setting of the text, is surely deliberate (or contrived) in bringing together such contrastive performances of femaleness for the purposes of entertainment. It is certainly a premise which Dame Edna exploits for its comedic potential. This is confirmed by Edna's explicit intra-textual social commentary. After all, if we consider the context in this way, we see a juxtaposition where a man, dressed as a woman, is performing female heterosexuality, at least by comparison with the woman dressed as a man who seems to be performing androgyny and/or homosexuality, and both compare (perhaps favourably) with a heterosexual woman who is performing an exaggerated role of femaleness. Together, rather than separately, these three performances of femaleness are working to subvert "assumptions [of] an unquestioned and unavoidable [social] reality" (Fairclough, 2003: 58).

This is not a new focus for Humphries, who has, over time, articulated through his character Edna an ironic representation of the type of social consensus on gender which he is subverting. Interestingly, Humphries not only regards such a concept worth focusing on, he also laments the restrictions placed on his comedy by media and political "censorship"typically from people who do not register the fact that Edna is a satirical character. He is reported as rejecting what he sees as the "new puritanism" (PA 2015) and asserting that in comedy "there are no rules" (Taylor 2015). Referring to the type of person who does not "get the joke" of Edna, Humphries is also reported as saying that "If you have to explain satire to someone, you might as well give up [...]. There is no more terrible fate for a comedian than to be taken seriously" (Feneley 2014). 
Viewed through this frame, then, it is clear that the entire "set-up" for Edna's humour is to enact a performance of gender subversion. Indeed, there are quite explicit cues for the reading of gender performance, both verbal and non-verbal (including clothing and mannerisms). These were easily picked up by the UWS student audience, where they served as triggers to invoke a negative response, and then resistance. They would, logically then, serve as easily recognisable cues to trigger positive responses, and acceptance, from an aligned (same-sex-attracted) audience. Before investigating this pre-disposed audience, it is important to briefly review two salient moments from the text (transcribed broadly) and see where these important triggers occurred.

\section{Excerpts from the Dame Edna text}

These excerpts taken from "The Dame Edna Treatment" (Humphries \& Northover 2007) are selected for their pivotal roles in triggering discursive responses from the audience. They were significant in the original studio recording (as evidenced by sustained audience applause and laughter), and they are also significant for their intrinsic richness in discourse features. The textual excerpts are rendered into a broad transcript, together with a brief summary of discourse features. Because this paper is focusing on the triggers themselves and the reception of these triggers, the discourse analysis will be necessarily brief and secondary to the discussion.

\subsection{Textual excerpt \#1}

Edna: I... think there's too much fuss about this gender business $\backslash$ ( 1 second pause) It's, I mean, there are whole articles, women's magazines, full of it/ (1) It's a sort of fad, really/ (.5) I think women might be too/ liberated .

k.d.: You do- (flat intonation)

Edna: I'm...do you get that feeling? /

k.d.: (2) Yesl

Audience laughs

Edna: (3) I'm...I think so. It's all overdone.

k.d.: Yes. Definitely, I...

Edna: (overlap, interruption) I think we are/ liberated $\backslash$ (...) Look at us...।

k.d.: I...I (1) Yes. I don't think we need to liberate any further... (overlapping, trails off)

Edna: -I mean, here we are, three very liberated women, chatting away like this.

k.d.: Yeah-\(laughs)

Ivana: (laughs).

Audience laughs

Comments: Bold items indicate significant contextualisation cues introduced by Edna which signal topic management and the play script (non-literal, which entails a flouting of Gricean Maxims; Grice 1975) used for setting up an ironic frame. Interestingly, it is clear from k. d.'s facial expressions that there is some negotiation of this play script (and her Face needs) required, until she accedes to the shared "joke". It is also clear that in the interests of the conversational goal (i.e., the joke) in the context of public performance, k. d. is willing to sacrifice her own Face needs. It is not clear if Ivana is an active participant, since her laugh seems to be insincere, or at least superficial, and she is not aware that she is the indirect target (or butt) of the joke itself. 


\title{
7.2. Textual excerpt \#2
}

\author{
Edna: I don't think that there's anything that two intelligent women cannot discuss.I \\ There's no taboo-(3) \\ k.d. and Ivana have serious facial expressions \\ Edna: I make no apologies for the words, for the terminology...(2) \\ Perhaps the coarse... (2) terminology that I'm going to use now. \\ k.d., Ivana, Edna and audience laugh (10 seconds) \\ Edna: When/ \\ k.d., Ivana, Edna and audience laugh (6 seconds) \\ Edna: When did you first know you were Canadian? \\ While audience, $k . d$. and Ivana laugh for 20 seconds, Edna says in a low pitch: \\ No...I mean...pleasel
}

Comments: Bold items again indicate major contextualisation cues which tap into background knowledge from the players and audience for k. d.'s sexual orientation and the naiveté entailed in the frame/line of questioning from Edna. Note also that the omission of Ivana in the deictic reference to " 2 intelligent women" (which is varied from the previous utterance including her as one of "3 very liberated women") may be inadvertent but it functions in the pursuit of solidarity: because k. d. is an active participant in the "set-up" of the joke, she becomes, along with an assumed "conservative social attitude" towards gay orientation, the butt of the joke. The joke itself relies on the replacement of the collocationally expected word ("lesbian", or perhaps "gay" or "homosexual") with "Canadian": what was likely to be quite embarrassing or confrontational turns out to be quite harmless. This is critical in the overall tone and intent of the humorous text, and it functions as a trigger for the acceptance or rejection of the text by the studio audience and by the viewing audience.

One major feature of these excerpts is the way in which Edna dominates the conversation. Note also the intuitive (and practised) use of silences, which are the mark of a professional comedian: sometimes they mark a pause while the audience laughs and Edna is waiting to continue, while at other times they indicate a sustained moment of comedic tension before the punch line. Used at critical times in the text, they vary from half of a second through to a full 20 seconds at the end of the excerpt. These permit Edna to control the pre-planned topics, floor and direction of the interview, since Edna as host is the only person who knows the "script".

Another point which is significant is that the genre of the chat-show is subverted by the need to entertain as a comedy. Indeed, this seems to be a defining feature of Humphries' comedic style, where the "interviewee isn't really there to be interviewed, but to play the part of famous straight man [sic] to the comic, the show's true star" (Cook 2007). This is one reason why the pre-disposed audience, which views the show primarily to see k. d., was selected; their responses would be a good measure of how k. d. fans would react to the gender triggers when $\mathrm{k}$. d. is not the principal star, and, thus, is potentially at risk of public humiliation. The selection of this audience was considered to be even more important, after it was found that many of the contributors were not familiar with Dame Edna. This meant that, while they were discursively pre-disposed to k. d., there was, in general, no bias towards or against Edna.

\section{The k. d. lang (same-sex-attracted) fan bloggers: an aligned audience}

In order to test the preliminary finding, as it relates to a non-aligned audience, it was decided to locate a distinctively aligned, or predisposed, k. d. lang (fan) audience and to evaluate their responses to this media text. From the comments collected, it was clear that most, if not all, fans of k. d. lang were also same-sex-attracted, since they self-identified as such. No data was 
collected on the basis of gender, since this was not, typically, considered to be important or even available. Only when a blogger did make a comment on the basis of gender, and where this was significant, was it noted. Neither was it possible to define this audience as being purely US-based, since many of the contributors either indicated that they from international locations, or did not identify nationality or location. This was not considered to be an important descriptor, so contextualisation of same-sex-attracted persons was based on data from the Australian context: for instance, that the LGBT community is a minority in the general community (at around 2\%) and that these persons typically (but not uniformly) endorse liberalprogressive ideologies.

For these reasons, this audience was selected on the basis of it being a type of discursive "opposite" of the UWS student audience. Whereas the UWS students were defined as highly conservative, this audience was expected to be liberal/progressive in its discourse, especially in regard to gender performance. This was assumed for two reasons: first, because they identified as being same-sex-attracted and thus, presumably would be more open to variations on performances of female heterosexuality; and secondly, because, consistent with Australian data for same-sex-attracted persons, it was highly likely that this audience would be "more highly educated [...] have higher incomes [and be] more likely to report having no religion" (ABS 2013b). This combination of demographics is highly indicative of persons who are more liberal-progressive for ideology (ABS 2013b). The assumption that the bloggers would be liberal-progressive in their outlook is supported by research which indicates that the "LGBT community"1 is actively involved in "progressive politics" and that many in the community self-define as being opposed to "conservative ideologues" (Wesley et al. 2011: 150-154). While of course there are many political and social variations within the LGBT community, this particular set of k. d. lang fan-bloggers was selected for being distinctive in that they were, by all indications, already aligned with the singer's liberal-progressive views. Thus, it was expected that they would, at least, be sympathetic to any performance of gender as presented in the text by k. $d$.

\section{The sample and data for the pro-k. d. lang audience}

The sample consisted of 377 comments from 58 individual (unique contributor) postings on three separate k. d. lang fan blogs which featured threads on the Dame Edna text/program. All comments were selected on the criterion of a clear reference to either k. d., Edna, or Ivana, and they also needed a specific "tag" relating to performance of gender. All other (at least 30) blog comments with no clear tag (either for name or for gender) were omitted from the selection. Some comments involved multiple references to both k. d. and Edna: these were counted as a comment for both, so some minor duplication was involved, but these accounted for only 14 comments overall.

Table 1. Summary of comments relating to main participants Individuals: 58 unique blog contributors.

Of these 377 total comments:

\begin{tabular}{|l|l|l|l|}
\hline Subject & Positive & Negative & Total references \\
\hline Dame Edna & 68 & 4 & 72 \\
\hline k. d. lang & 251 & 8 & 259 \\
\hline Ivana Trump & 0 & 46 & 46 \\
\hline
\end{tabular}




\section{Discussion of results}

\subsection{Ivana commentary}

It is clear from these results, that the overall tone of comments was favourable towards $\mathrm{k} . \mathrm{d}$. and Edna, and very unfavourable towards Ivana. The significance of this is that, as expected, the pre-disposed audience was prepared to accept non-traditional gender comments and performances from Edna and k. d. By contrast, there was a distinctly prejudicial tone of comments targeting Ivana. This high focus on Ivana is especially surprising, given the very minor role that she played overall in the text. All 46 comments can be described as particularly hostile towards Ivana's gender performance, given that most focused on her appearance and her lack of active participation (i.e. relating to a-presumed-limited cognitive awareness of proceedings). There was also an assertion made in some of the comments that Ivana is somewhat homophobic. Threads of commentary indicated that all these criticisms ultimately and cumulatively related to Ivana's performance of gender, including the referential reductionism of her as a "trophy wife", or "gold-digger".

It can be argued that an audience pre-disposed to gender subversion would, predictably, focus on k. d. or Edna, and this was indeed the case; only a minority of comments overall presented opinions on Ivana. The bloggers typically identified for same-sex attraction, so there was also an expectation that some same-sex attraction normativity would be present. The fact that Ivana was singled out for comments at all tends to validate this expectation, since she is the exception to this normative textual environment, being perceived as variant from the text's presumed "agenda".

So, for instance, some comments critical of Ivana are (not corrected for grammar, including punctuation), with tags in bold:

"Ivana can't even crack a smile due to all the plastic surgery."

"Wow! Ivana looked so uncomfortable and kept 'leaning away'. Don't worry Ivana, I'm sure

K.D. Lang wants to keep her money."

"just way above her brain power to comprehend, me thinx."

"That plastic store window dummy on the right moves on it's own????????"

"Ivana might have smiled more if her very taut face had allowed it."

\subsection{Edna commentary}

Comments directed towards Edna were, by contrast, more favourable than for Ivana. As expected, there were fewer comments directed at Edna, since the blogs were primarily focused on k. d. Of those which commented on Edna, the majority were favourable. Nevertheless, one particular minor thread of commentary, which was presented by (self-identified) gay men, questioned Edna's cross-dressing performance. There appeared to be some conflict here between (perceived) transphobia and resentment at a heterosexual performer in drag performing gender subversion. Two gay men also negatively linked k. d.'s suit-attire to Edna's cross-dressing; even while simultaneously denying any prejudice. These are interesting in their own right, expressing an awareness of what could be referred to as a same-sex-attracted normative environment (since the blogs were fan sites for $\mathrm{k}$. d. lang), while also responding to what seemed to be a more personal discursive conflict. Perhaps these can be interpreted as a healthy questioning of the authorial agenda of the text, but also as a minority within a minority 
which is sensitive to wider social norms, and thus emblematic of the diversity within the LGBT community.

Examples of these negative and ambivalent comments include:

"An old man dressed as a woman and young woman dressed like a man. This is very strange and ironic."

"funnily enough, $i$ dont have any prejudices. let people be what they want to be, but, a guy in a dress and a girl in a suit, not for me. $i$ may add, that, if $i$ ever met (again) a guy in a dress, and a girl in a suit, who cares. (unprejudiced! still dont look right) bye!"

"Darn [sic] Edna was lousy!"

\section{3. k. d. commentary}

Overwhelmingly, comments were positive for $\mathrm{k}$. d., which is predictable from an aligned audience in fan-centric blogs. In this category, most noted that $\mathrm{k}$. d. was an active participant in the creation of the comedy, even though, or especially because, she was at risk of Face-loss. Comments typically referred to her as a "great sport" which is a succinct way of describing this Face-risk: a good-natured way of acceding to comedy where the participant is the focus of the humour. Some comments explicitly linked k. d.'s willing participation in the show's humour as enhancing her sexual attractiveness, which is interesting, given that there is some extant literature linking sexual attraction to humour (e.g., Bressler \& Bashine 2006; Bressler et al. 2006; Greengross \& Miller 2011). From this, we can assume that k. d.'s good-natured acceptance of Edna's teasing did not in any way damage her following, and probably enhanced it. Many comments linked k. d.'s "professionalism" with her performance of comedy and they also tended to personalise these linkages. So, for example, there were assertions made that $\mathrm{k}$. d. was a "true professional" in this context, which also linked to claims that this made her a "wonderful person". By contextual inference, this type of comment indicated that k. d.'s acceptance of humour relating to her sexual orientation was clearly a trigger for many contributors. Another way of interpreting this is to say that $\mathrm{k}$. $\mathrm{d}$. was recognised as being very self-confident in her sexual orientation, even while being teased about it in a public setting.

There were a few negative comments and, as noted above, some comments which were negative towards Edna (by gay male bloggers) included k. d. in their comment by association, and these were included in the negative count for $\mathrm{k}$. $\mathrm{d}$. as well.

Examples of positive comments include:

"I love this. K.D comes across as a fantastic person. She just sits there, no ego, no trying to match wits, no taking offence, totally getting the humour and understanding the context of the situation. What you have is a person utterly at ease and thoroughly enjoying themselves. It's really joyous to watch."

"K D's such a good sport."

"there are some superb near references to KD's sexuality which are very funny and well handled by KD, who looks wonderful."

"I'm afraid I will dream of her now. Or in any case about beautiful suitwearing butches with a great voice and a lovely smile."

"Classic Dame Edna....and Ms. Lang serves rather well in the role of "straight person" (er, unfortunate choice of words). That she managed to keep from cracking up through the entire routine shows just what a true professional she is."

"K D prevailed in every way, well done and cheers Lang."

"This scene is so eccentrically funny, with three people who couldn't be more different lol. It's like a fabulous showbusiness mental home-but I love them and am a huge fan of K.D.Lang $\boldsymbol{x}$ " 


\subsection{Media reviewers}

Using the same tags for gender, four mainstream media reviews of the programme were identified and investigated for instances of discursive triggers. The media reviews were taken from The Sydney Morning Herald (Enker 2007) and The Guardian (Cook 2007): all are prominent entertainment commentators. These media reviews were selected on the basis of them representing mainstream community attitudes. The UK and Australian newspapers were considered to be comparable as quality broadsheet forms of media, and thus would be broadly similar discursively, considering that Dame Edna is at least as familiar to British audiences as she is to Australian audiences. For the purposes of this study, the media from the UK and Australia were treated as being similar enough: similarities were more important than any differences. This was borne out by the very similar reviews across the Australian and UK media reports.

Thus, there was some assumption made that the media commentators would be representative of mainstream liberal-progressive ideologies. Indeed, this assumption was more than vindicated, not by what the reviewers said, as by what they did not say. That is, the reviewers were uniformly negative for Edna's humour, while tags for gender performance were absent, except as simple pronominal referents. This indicates that Edna's gender performance is considered to be unmarked, which is discursively significant: it indicates that the crossdressing comedian is unremarkable through long-term familiarity. It also suggests that Edna is, for these reviewers (and perhaps to some extent also their readership, and the wider UK and Australian audiences), not only very familiar, but also rather tedious through repetition. The fact that explicit references to Ivana and $\mathrm{k}$. d. lang were also noticeably absent indicates that the focus of the media reviewers was on Edna's humour performance, and that gender performance was considered to be unexceptional. This suggests that for mainstream communities in Australia (and by extension the UK) there seems to be high tolerance for variant gender performance, especially in the entertainment industry.

By contrast, what was most apparent in the reviews was the nature of the criticisms of Edna's comedic style and authorial agenda- but not for gender performance. Reviewers were highly critical of Edna's barbed style of "irony". Even when admitting some appeal for Edna as a character, most critics did not enjoy Humphries' innuendos and personal targeting. There was only one explicit reference to the guests, with one reviewer adopting an ambiguous attitude towards k. d., simply noting that "k. d. laughs a lot". (Enker 2007).

Examples include:

"Although his menopausal Melbourne housewife is one of TV's funniest creations, the prospect of yet another round of "ironic" interviews makes the heart sink." (Cook 2007).

"Edna was created in the late '50s as an average housewife from Moonee Ponds [...]. He can be deeply cruel and icily vicious. If there is still an intellectual point to Humphries' performance today, it's too often lost in the murk of his tastelessness, swamped by his scatological and anal obsessions." (Farrer 2007).

"But, of course, this particular chat show [...] is only nominally about the guests, it's all about Edna-who's not that interested in the people on the couch, or the gifts they might graciously offer her. She wants to talk about her favourite subject, herself [...]. The guests are only there to give her something to bounce off" (Enker 2007). 


\section{General discussion}

A major commonality of these comments is that the $\mathrm{k}$. $\mathrm{d}$. fan base was overwhelmingly positive towards the text. The few negative comments directed towards $\mathrm{k}$. d. were typically from individuals who did not positively receive the triggers of cross-dressing; yet these were typically from (self-identified) gay males, and they also rejected Edna for the same reason. It was expected that a gay audience would be fairly uniform in its acceptance of cross-dressing, but for some individuals this was a trigger that seemed insurmountable; it skewed their response to the text. What was intriguing about this type of comment was the way in which these comments presented what can be described as a "conflicted" response, and this is key to the way in which triggers operate. While self-identifying as gay males in a clearly pro-lesbian forum, and indicating "loyalty" to the same-sex community, some individuals asserted the right to dissent. Some even took a thread of discussion into the (claimed) lesbian-only appeal of k. d. while asserting gay "credentials". So for example, one gay male's comment was to credentialise with this comment: "and before you accuse me of being homophobic, then don't. I'm a 'same sexer' myself'.

The significance of such comments is that they indicate how loyalty to cultural identity and social cohesion is triggered by salient textual features. Indeed, the same text operates for the prominent trigger of gender in very similar ways. What all respondents have in common is that they quickly identified the authorial agenda of gender subversion as a central feature of the text - the different audiences, however, diverged according to pre-disposition. UWS students in the non-aligned audience were able to analyse the text effectively, but they signalled cultural identity and social cohesion by an explicit rejection of the authorial agenda, and by association, the text itself as humorous.

The aligned audience also picked up on the authorial agenda of gender subversion very quickly, but their responses were more complex. Some gay men, for instance, wanted to signal allegiance to a wider LGBT community (although this initialism did not appear anywhere as a referent), but they rejected the gender trigger of cross-dressing. Even as they did so, they asserted a lack of prejudice - which is, in itself, a clear trigger of social cohesion. That is, they did not want to appear as disloyal to the community by having a dissenting opinion, and they were careful to signal this. Similarly, the majority of contributors referenced the trigger of gender (and gender subversion) in their responses, and signalled community allegiance as they did so. Some of these were explicit in their linking of k. d.'s sexual orientation and her performance of gender in the text. Others found associations between k. d.'s sexual attractiveness and her performance of gender, with her demonstration of humour. Almost all were positive in their identification of gender triggers, and k. d. in particular, as articulating these triggers.

By association, most blogger contributors were also positive towards Edna, even though the character was teasing in her humour, because this was interpreted as being favourable to $\mathrm{k}$. $\mathrm{d}$., and in allowing k. d. to demonstrate her comedic (and by implication, her personal) appeal. Again, the triggers for Edna were also explicitly gendered, particularly where those triggers related to k. d.'s sexual orientation. Most respondents did not isolate Edna's cross-dressing, but they did approve of Edna's implicit endorsement of $\mathrm{k}$. $\mathrm{d}$. This taps into the surprising feature of the comments, which were especially virulent in their negativity directed against Ivana. While unexpected, this negativity is explicable. Ivana, even though a passive participant in the text, represented, for most respondents, the normative heterosexual society which was the target of Edna's humour. While ostensibly directed against k. d., it is evident that the real target of Edna's humour is the intolerant wider community - a fact that most respondents seemed to pick up on. Edna's triggers, which included items such as taboo, coarse, liberated/intelligent women, gender business, women's magazines, tap into, reference, frame, and trigger audience 
expectations of social attitudes towards k. d.'s sexual orientation. Ivana, as a representative of this wider community, and almost as a caricature of gender superficiality, becomes, by default, the image and vehicle of irony. She also becomes the catalyst for social cohesion; respondents indicate their social cohesion and group identity by explicitly identifying her as the symbol of heterosexual otherness. By targeting Ivana, they can credentialise as "authentic" gay persons.

Interestingly, a similar targeting occurred with the student audience: Ivana became the "other", not because of her heterosexuality, but because of her non-conservative clothing. By criticising Ivana (for instance) for "showing too much skin", students validated their membership of a conservative community. The common link between the two audiences is that respondents easily identify gender triggers and filter them according to the community to which they wish to demonstrate allegiance. It would appear then, that social cohesion and group identity are powerful forces which factor prominently when all other literacy requirements are met.

And finally, the wider community audience, as represented by the mainstream media reviewers, was significant for its lack of interest in textual gender performance. Rather, the reviewers were more focused on the ways in which Edna's humour was "cruel" and "vicious" or perhaps it can be paraphrased as describing Edna as a character past its "use-by-date". In other words, the reviewers looked beyond the various gender performances in the text, to the comedic style of Barry Humphries' most famous character. It is almost as though gender performance was invisible for the wider community, because it is familiar and routine, even mundane. In this case, the reviewers' response to the text can be described as negative, not because the performer or textual type is unfamiliar, or because they were unable to distinguish gender triggers, but because all of these criteria were satisfied, and the reviewers responded to the authorial agenda, which they found to be cynical and manipulative.

\section{Conclusion}

This paper set out to test the impressions gained from a preliminary observation, which indicated that literacy was a foundational requirement, but not the most important factor, for a cohort of conservative students in responding to a humorous text. It found that respondents typically filtered a text for triggers which undermined their social allegiances. It was also found that these respondents, who possessed adequate to high literacy in the English language, were able to analyse a humorous text, but did not enjoy that text for discursive reasons. They were adept at identifying the authorial agenda for threats to their ideology and cultural allegiances, and consequently resisted the text. As a conservative group of respondents, this group was defined as non-aligned for such a text, and their response was negative towards the text. The important trigger of gender was identified as the salient feature in this response.

To test the premise that we are motivated to resist texts, particularly humorous texts, which we feel compromise our identity and social allegiances, a group of more aligned respondents was located. Adequate to high literacy was assumed in this sample, based on the context. It was also assumed that such a group would demonstrate an opposite response to that of the preliminary study group (being representative of a highly liberal-progressive community, the LGBT community), but that this response would be similarly triggered by the same feature of gender-performance. This was certainly found to be the case, even though there some complex, or ambivalent, responses. Gender performance was the most prominent trigger, and it was used to signify group-cultural allegiance: in this case same-sex-attraction was the aligning feature. Indeed, respondent enjoyment of the text was determined to be conditional on the active construction of the humour by k. d. lang in collaboration with Dame Edna. Even the bloggers' criticisms of Edna and Ivana were, contextually, conditional on the performance of gender 
relative to $\mathrm{k}$. $\mathrm{d}$. Somewhat surprisingly, the most strident criticisms of gender performance were reserved for Ivana, who was targeted as a symbol of wider social normative constructions of heterosexual gender performance. Overwhelmingly, then, this audience demonstrated a positive reception of the text, and they were explicit in their articulation of gender performance as being integral to this positive reception of the textual humour and authorial agenda.

These responses were then compared to the mainstream media reviews of the text. These media reviewers were assumed to represent more mainstream community attitudes towards gender performance. In the context of a wider Australian population, these media reviewers were designated as being representative of a general liberal-progressive discursive position. Indeed, the fact that the reviewers seemed to rapidly move beyond the gender performance triggers that the other two audiences focused on, indicates that this assumption was correct. It confirmed that the reviewers had both the literacy for this type of humour and the background knowledge of previous Edna humorous texts. This data evidences the possibility that an audience with a high tolerance for variant gender performance as a matter of discursive liberal/progressivism will actually have a superior ability to process gender triggers within a humorous text which is both familiar and aligned with this type of discourse. They were able to move beyond these salient triggers to an evaluation of the text which was negative, because they engaged in a more literate sense with the authorial agenda, and they found it to be cynical and manipulative. This indicates an intriguing possibility for future research which is that, when it comes to humour, 'familiarity breeds contempt'. That is, even when we are discursively aligned with an authorial agenda, and we have enjoyed a humourist's performances in the past, the very triggers which were appealing at first (and which, indeed, were perhaps the source of much of the humour) may simply cease to work for us, through over-familiarity. We may then start to identify the "cracks" in our group solidarity, and become more selective, even defensive, in our reception of that humourist's texts in future.

In summary then, this study provides evidence for the theory that we are conditioned to accept a humorous text on the basis of in-group solidarity. The text becomes symbolic of, and a test of, our group identity. Of course, any acceptance of humour is conditional on literacy, so that we need to be able to "get the joke" in the first place. To not have this literacy adequate for the decoding of a humorous text, is to not move beyond an inert response because the text does not invoke a discursive reaction. It makes no demands on our discourse and it does not challenge our group identity if we cannot understand what is being communicated. But, if we do have the literacy to decode the text, we then move beyond literacy to the filter of discourse, where we decide if a joke is in our best interests. There is no automatic causative link between "getting the joke" and "enjoying the joke", and it would appear that we are highly motivated to resist humour when it compromises our deepest-held allegiances. Indeed, we are not only good at resisting the humorous text when it threatens our discursive alignment; we are also adept at identifying the triggers of the text's authorial agenda. Similarly, we are pre-disposed to enjoy, or positively receive the humorous text when we recognise the triggers for discursive alignment. Contrary to expectations, perhaps, rather than being an indication of poorer literacy, discursively rejecting or accepting a text on the basis of its authorial agenda, and being able to explain why this occurs, can indicate higher literacy.

\section{Notes}

${ }^{1}$ This initialism refers to the Lesbian, Gay, Bisexual and Transgender (LGBT) community. It is also referred to as the Lesbian, Gay, Bisexual, Transgender and Intersex (LGBTI) community, and there are other less commonly used variations. 


\section{Appendix}

Transcription conventions

The following symbols are used in a broad transcription of the data:

... Elision marks, indicating a brief pause or hesitation which is less than half a second in duration.

( ) Parenthetical information indicating prosodic elements such as: significant pauses, e.g. (2 seconds of silence); or information relating to the speaker's prosodic delivery, e.g. (voice trailing off).

Bold lexical items which are stressed by the speaker, and which are often louder than surrounding items.

Italics Ambient elements, often non-verbals or other prosodic items which contribute to the text, but which are more incidental to the propositional content.

$\backslash \quad$ Falling intonation.

/ Rising intonation.

\section{References}

ABS: Australian Bureau of Statistics. (2012). '2071.0 - Reflecting a Nation: Stories from the 2011 Census, 2012-2013'. Available online: http://www.abs.gov.au/ausstats/abs@.nsf/Lookup/2071.0main+features902012-2013 [Accessed on 25 September 2016].

ABS: Australian Bureau of Statistics. (2013a). '2011 Census QuickStats: All people - usual residents'. Available online: http://www.censusdata.abs.gov.au/census_services/getproduct/census/2011/quickstat/0 [Accessed on 25 September 2016].

ABS: Australian Bureau of Statistics. (2013b). '4102.0 - Australian Social Trends, Nov 2013: Losing My Religion'. Available online: http://www.abs.gov.au/ausstats/abs@.nsf/Lookup/4102.0Main+Features30Nov+2013 [Accessed on 25 September 2016].

Attardo, S. (1994). Linguistic Theories of Humor. New York: Mouton de Gruyter.

Berger, P. L. (1997). Redeeming Laughter: The Comic Dimension of Human Experience. New York: Walter de Gruyter.

Bourdieu, P., Passeron, J. \& de Saint Martin, M. (1994). Academic Discourse: Linguistic Misunderstanding and Professorial Power. Transl. by Teese, R.). Cambridge (UK):Polity Press.

Bressler, E.R., Martin, R.A, \& Balshine, S. (2006). 'Production and appreciation of humor as sexually selected traits'. Evolution and Human Behavior 27 (2), pp. 121-130.

Bressler, E.R. \& Balshine, S. (2006). 'The influence of humor on desirability'. Evolution and Human Behavior 27 (1), pp. 29-39.

Breward, I. (1988). Australia: The Most Godless Place Under Heaven? Melbourne: Beacon Hill Books.

Cameron, D. (2005). 'Language, Gender, and Sexuality: Current Issues and New Directions'. Applied Linguistics 26 (4), pp. 482-502. 
Canale, M. (1983). 'From communicative competence to communicative language pedagogy'. Language and communication 1(1), pp. 1-47.

Canale, M., \& Swain, M. (1980). 'Theoretical bases of communicative approaches to second language teaching and testing'. Applied linguistics 1(1), pp. 1-47.

Carey, J. (2003). 'Introduction', in Freud, S., The Joke and Its Relation to the Unconscious, Transl. by Crick, J. London: Penguin, pp. xxviii.

Celce-Murcia, M. (2007). 'Rethinking the role of communicative competence in language teaching', in Intercultural Language Use and Language Learning, Netherlands: Springer, pp. 41-57.

Chapman, A. J. (1983). 'Humor and laughter in social interaction and some implications for humor research', in Handbook of Humor Research, New York: Springer, pp. 135-157.

Cook, W. (2007). 'Dame Edna's chat show has run out of gas.' The Guardian, Available online: https://www.theguardian.com/culture/tvandradioblog/2007/mar/16/dameednaschatshowfo rmatha [Accessed on 10 December 2015].

Cox, L. (2014). 'Poll shows growing support for same-sex marriage'. The Sydney Morning Herald, Available online: http://www.smh.com.au/federal-politics/political-news/pollshows-growing-support-for-samesex-marriage-20140714-3bxaj.html [Accessed on 25 September 2016].

Critchley, S. (2002a). On Humour (Thinking in Action). London: Routledge.

Critchley, S. (2002b). 'Did You Hear The One About The Philosopher Writing A Book On Humour?' Richmond Journal of Philosophy 2, pp. 1-6.

Doane, M.A. (2004). 'Film and the Masquerade: Theorising the female spectator', in Schatz, T. (ed.), Hollywood: Cultural Dimensions: Ideology, Identity and Cultural Industry Studies, Volume IV, London: Routledge, pp. 95-110.

Dryzek, J. S. \& Kanra, B. (2014). 'Australian Muslims' orientations to secular society: Empirical exploration of theoretical classifications'. Journal of Sociology 50 (2), pp. 182198.

Enker, D. (2007). 'The Dame Edna Treatment: The great dame celebrates 50 years in show biz. Long may she reign'. The Sydney Morning Herald, Available online: http://www.smh.com.au/news/tv-reviews/the-dame-ednatreatment/2007/08/31/1188067348070.html [Accessed on 25 September 2016].

Fairclough, N. (2003). Analysing Discourse: Textual Analysis for social research. London: Routledge.

Farrer, G. (2007). 'The Dame Edna Treatment: Barry Humphries is much better than what he has become.' The Sydney Morning Herald, Available online: http://www.smh.com.au/news/tv-reviews/the-dame-ednatreatment/2007/08/24/1187462502942.html [Accessed on 10 December 2015].

Feneley, R. (2014). 'Poetry professor Barry Spurr: master of parody or bigotry?'. The Sydney Morning Herald, Available online: http://www.smh.com.au/national/poetry-professorbarry-spurr-master-of-parody-or-bigotry-20141024-11azyf.html [Accessed on 25 September 2016].

Fine, G. A. \& de Soucey, M. (2005). 'Joking cultures: Humor themes as social regulation in group life'. Humor 18 (1), pp. 1-22.

Greengross, G. \& Miller, G. (2011). 'Humor ability reveals intelligence, predicts mating success, and is higher in males'. Intelligence 39, pp. 188-192.

Grice, H. P. (1975). 'Logic and conversation', in Cole, P. \& Morgan, J. L. (eds.), Speech Acts, New York: Academic Press, pp. 41-58.

Gruner, C. R. (2000). The Game of Humor: A Comprehensive Theory of Why We Laugh. New Brunswick, USA: Publisher Transaction Publishers. 
Hassan, R. (2006). 'Expressions of religiosity and blasphemy in modern societies', in Burns Coleman, E. \& and White, K. (eds.), Negotiating the Sacred: Blasphemy and Sacrilege in a Multicultural Society, Canberra: ANU E Press, pp. 119-132.

Hertzog, T. R. \& Anderson, M. R. (2000). 'Joke cruelty, emotional responsiveness, and joke appreciation'. Humor 13 (3), pp. 333-351.

Holmes, J. \& Marra, M. (2002). 'Over the edge? Subversive humor between colleagues and friends'. Humor 15 (1), pp. 65-88.

Humphries, B. (Writer) \& Northover, J.F.D. (Director). (2007). 'Episode 7: Excerpt'. The Dame Edna Treatment. London: Tiger Aspect Productions \& Independent Television (ITV). Available online: https://www.youtube.com/watch?v=nW7HLqOgM20 [Accessed on 25 September 2016].

Hyers, L. L. \& Hyers, C. (2008). 'Everyday discrimination experienced by conservative Christians at the secular university'. Analyses of Social Issues and Public Policy 8 (1), pp. 113-137.

IMDb (2015). 'The Dame Edna Treatment, 2007'. Available online: http://www.imdb.com/title/tt0983954/?ref_=ttfc_fc_tt [Accessed on 25 September 2016].

Kelley, J. (2001). 'Attitudes towards homosexuality in 29 nations'. Australian Social Monitor 4 (1), pp. 15-22.

Kintsch, W. (1998). Comprehension: A Paradigm for Cognition. Cambridge: Cambridge University Press.

Kintsch, W. (2005). 'An overview of top-down and bottom-up effects in comprehension: The CI perspective'. Discourse Processes 39 (2-3), pp. 125-128.

Koestler, A. (1964). The Act of Creation. New York: Dell.

Lee, D. \& Gunesekera, M. (2006). 'Humor in spoken academic discourse'. NUCB Journal of Language, Culture and Communication 8 (3), pp. 49-68.

Levinson, S. (1983). Pragmatics. Cambridge: Cambridge University Press.

Lockyer, S. \& Pickering, M. (eds). (2009). Beyond a Joke: The Limits of Humour. Basingstoke: Palgrave Macmillan.

Mayerhofer, B., Maier, K., \& Schacht, A. (2015). 'Priming interpretations: Contextual impact on the processing of garden path jokes'. Discourse Processes pp. 1-20.

McDonald, P. (2000). 'Gender equity, social institutions and the future of fertility'. Journal of the Australian Population Association 17 (1), pp. 1-16.

Nesi, H. (2012). 'Laughter in university lectures'. Journal of English for Academic Purposes 11 (2), pp. 79-89.

Oliver, R. (2007). 'The Dame Edna Treatment'. The Sydney Morning Herald, Available online: http://www.smh.com.au/articles/2007/07/20/1184560018303.html [Accessed on 25 September 2016].

PA. (2016). 'Barry Humphries slams BBC's 'puritanism'. The Sydney Morning Herald,

Available online: http://www.smh.com.au/entertainment/tv-and-radio/barry-humphries-slamsbbcs-puritanism-20160105-glzuhf.html [Accessed on 25 September 2016].

Parashar, A. (2012) 'Australian Muslims and family law: Diversity and gender justice'. Journal of Intercultural Studies 33 (5), pp. 565-583,

Powell, R., Pepper, M. \& Hancock, N. (2016). 2011 NCLS Research Collection - Revised edition, March 2016 Catalogue number 4.16.001. Sydney: NCLS Research.

Raskin, V. (1985). Semantic Mechanisms of Humor. Dordrecht: Reidel.

Reid, A. (2006). 'Key competencies: a new way forward or more of the same?' Curriculum Matters 2 (1), p. 43.

Ross, A. (1998). The Language of Humour. London: Routledge. 
Stevens, C. R. \& Campbell, P. J. (2008). 'Collaborating with librarians to develop lower division political science students' information literacy competencies'. Journal of Political Science Education 4 (2), pp. 225-252.

Taylor, A. (8 June 2015). 'Adelaide Cabaret Festival: Dame Edna, a Russian beautician and Pauline Hanson steal the show'. The Sydney Morning Herald, Available online: http://www.smh.com.au/entertainment/music/adelaide-cabaret-festival-dame-edna-arussian-beautician-and-pauline-hanson-steal-the-show-20150608-ghip1p.html [Accessed on 25 September 2016].

Tolson, A. (1991). 'Televised chat and the synthetic personality', in Scannell, P. (ed.), Broadcast Talk, London: Sage, pp. 178-200.

Turnbull, S. (2008). 'Mapping the vast suburban tundra: Australian comedy from Dame Edna to Kath and Kim'. International Journal of Cultural Studies 11 (1), pp. 15-32.

University of Western Sydney. (2013). Student Demographics Report Pre-Assessment 2012 Autumn [Data file]. Penrith: UWS.

University of Western Sydney. (2015). Unit Demographic Results Snapshot: Unit $\quad$ 102325, Level 7, Advanced Academic English Skills [Data file]. Penrith: UWS.

University of Western Sydney. (no date). 'Working at UWS: Who we are'. Available online: http://careers.uws.edu.au/Working-UWS/Who-we-are [Accessed on 19 March 2015].

Vertinsky, P. (2002). 'Sporting women in the public gaze: Shattering the master narrative of aging female bodies'. Canadian Woman Studies 21 (3), pp. 58-63.

Weaver, S. (2013). 'A rhetorical discourse analysis of online anti-Muslim and anti-Semitic jokes'. Ethnic and Racial Studies 36 (3), pp. 483-499.

Wesley, J. M., Hendrix, E. D., \& Williams, J. N. (2011). 'Moving forward: Advancing lesbian, gay, bisexual and transgender rights under the Obama administration through progressive politics'. Race, Gender \& Class 18 (3), pp. 150-168.

Western Sydney Region of Councils (WSROC). (2013). 'WSROC region: economic profile'. Available online: http://economy.id.com.au/wsroc [Accessed on DAY MONTH YEAR].

White, A. (2007). 'Muslim University Students in Australia: an insider's view'. Available online:

http://www.westernsydney.edu.au/equity_diversity/equity_and_diversity/cultural_diversit y/past_events/conference_documents/muslim_university_students_in_australia_-_part_1 [Accessed on 10 December 2015].

Wilson, J. \& Stapleton, K. (2007). 'The discourse of resistance: Social change and policing in Northern Ireland'. Language in Society 36 (3): pp. 393-425.

Wink, P., Dillon, M., \& Prettyman, A. (2007). 'Religiousness, spiritual seeking, and authoritarianism: Findings from a longitudinal study'. Journal for the Scientific Study of Religion 46 (3), pp. 321-335.

Wodak, R. (1997). Gender and Discourse. London: Sage.

Wulff, S., Swales, J. M., \& Keller, K. (2009). "We have about seven minutes for questions": The discussion sessions from a specialized conference'. English for Specific Purposes 28 (2), pp. 79-92. 